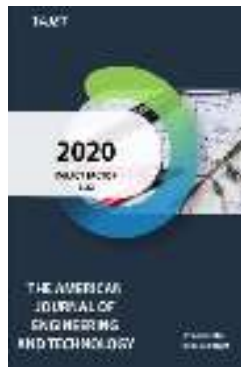

\title{
Guides Development For The Female'S Outerwear Models Collection, Taking Into Account The Operational Property Features Of Knitted Fabrics
}

\author{
Nargiza Nabidjanova \\ Namangan Institute Of Engineering And Technology, Namangan, Uzbekistan
}

\begin{abstract}
Journal Website: http://usajournalshub.c om/index,php/tajet

Copyright: Original content from this work may be used under the terms of the creative commons attributes 4.0 licence.
\end{abstract}

\section{ABSTRACT}

The article presents the theoretical and practical research results on many female's outer knitwear models collections development made from polycomponent raw materials.

\section{KEYWORDS}

Proportion, color, texture, ornament, collection, range of material, extensible, low stretch, multicomponent, raw.

\section{INTRODUCTION}

The developed model or prototype of knitwear helps to see the product shape conceived by the designer or constructor. Its proportions, color, texture, ornament and purpose. The preliminary sketches result is the first creative solution for a new product. A product sample reproduction in large series is the main feature of the production industrial method [1].

The greatest interest from the point of view of obtaining patterned weaves and products variety are universal automated flat knitting machines for making coupons with selection mechanisms that ensure needles individual selection.

The pattern-forming universal automated flat-fanged machines capabilities have been significantly expanded, which makes it possible to obtain multicolor ornaments in combination with purl loops, knitted fabrics with openwork and embossed effects, 
a pattern combination with all kinds of weave structures.

At the Republic enterprises, knitwear is produced mainly from pure cotton yarn or mixed with chemical threads, using various types and classes of knitted machines.

\section{RESULTS AND DISCUSSIONS}

The results obtained and the knowledge accumulated on the theoretical and experimental studies base have created the prerequisites for technological requirements recommendations formation for knitted outerwear from polycomponent raw materials.

1. The outer knitwear quality developed from multicomponent raw materials should be determined by correct modeling methods of knitwear structure, individual knitted parts design and completing.

2. Outer knitwear developed from multicomponent raw materials should have a

Table 1.

Recommended assortiment of multicomponent raw materials for the development of outerwear jerseys

\begin{tabular}{|c|c|c|c|}
\hline Type of machine & $\begin{array}{c}\text { Used composition of raw } \\
\text { materials (\%) }\end{array}$ & $\begin{array}{c}\text { Linear fabric } \\
\text { blended yarn } \\
\text { and yarn(tex) }\end{array}$ & Manufactured products \\
\hline CIXSING & Tensile canvases & Womens pullovers \\
5-7 class & $\begin{array}{c}\text { Cotton yarn (58\%) } \\
\text { Silk thread (37\%) }\end{array}$ & $\begin{array}{c}50 \times 4 / 1 \\
12,5 \times 4 / 2\end{array}$ & $\begin{array}{c}\text { Jacets, blouses, skirt, } \\
\text { leggings and children's suits }\end{array}$ \\
& $\begin{array}{c}\text { lycra (5\%) } \\
\end{array}$ & & \\
\hline
\end{tabular}

good fit on the figure, rational sizes and shape, depending on the stretch group of the knitted fabric, ensuring a comfortable state of the person.

3. The outer knitwear seams must be strong, without cutting defects to loosening the buttonhole conditions, have tightened stitches [2]. For sewing and overcastting machine seams, it is recommended to use synthetic, complex and cotton-lavsan sewing threads with 34 to 40 tex density linear, as well as sewing threads from natural silk with an appropriate linear density (33 to 60 tex).

The outerwear models guiding collection development made from poly-component knitwear was the next stage goal of work. Thedeveloped knitwear samples served as the initial information for choosing the outer knitwear shape, its proportions, texture and other collection style features. 


\begin{tabular}{|l|c|c|c|}
\hline & $\begin{array}{c}\text { Tensile convases } \\
\text { Cotton yarn (50\%) }\end{array}$ & $\begin{array}{c}\text { pullover, jumper, Jacets," } \\
\text { skirts, sweater, trousers } \\
\text { and vests }\end{array}$ \\
Silk thread (45\%) & $\begin{array}{c}50 \times 4 / 1 \\
12,5 \times 4 / 2\end{array}$ & \\
& lycra (5\%) & $4,44 \times 1$ & \\
\cline { 2 - 4 } & Low stretch canves & & Shapeless womens blouses \\
Cotton yarn (54\%) & $50 \times 4 / 1$ & \\
& Silk thread (46\%) & $12,5 \times 4 / 2$ & \\
\hline
\end{tabular}

Particular attention was paid to the models sketches creation to ensure that the aesthetic features correspond to modern fashion trends and marketing research demand results. On the other hand, the sketch collection was aimed at the products industrial designs preparation in industrial production.

When forming models collection sketches, psychophysiological requirements for modern clothes were also taken into account; physical and mechanical properties of new knitwear; identified knitting and sewing machines technological capabilities to reproduce conceived forms. The recommended multicomponent outer knitwear assortment, taking into account the new knitwear properties, is presented in table. 1.

As can be seen from table 1 the OK assortment includes: (jackets, trouser suits, shapeless blouses, skirts, half-overs). This shows the wide possibilities of using new canvases for the various species structures products manufacture.

The basic combinations selection in the collection was carried out on five-dimensional combinations distributions base of the various species main CSLKFI sets, found in the consumer preferences space.

To achieve clothing completeness and ensure a variety, the best option for designing CDMDII is a matrix design method.

At the same time, the matrix elements in this work are transformed elements and models. The method essence lies in the optimal decomposition principles application of the product structure, combinatorics, repeatability, interchangeability, compatibility of composition and unified structural elements variant transformations, providing real conditions for updating models with minimal loss of production volumes $[3,4]$. 


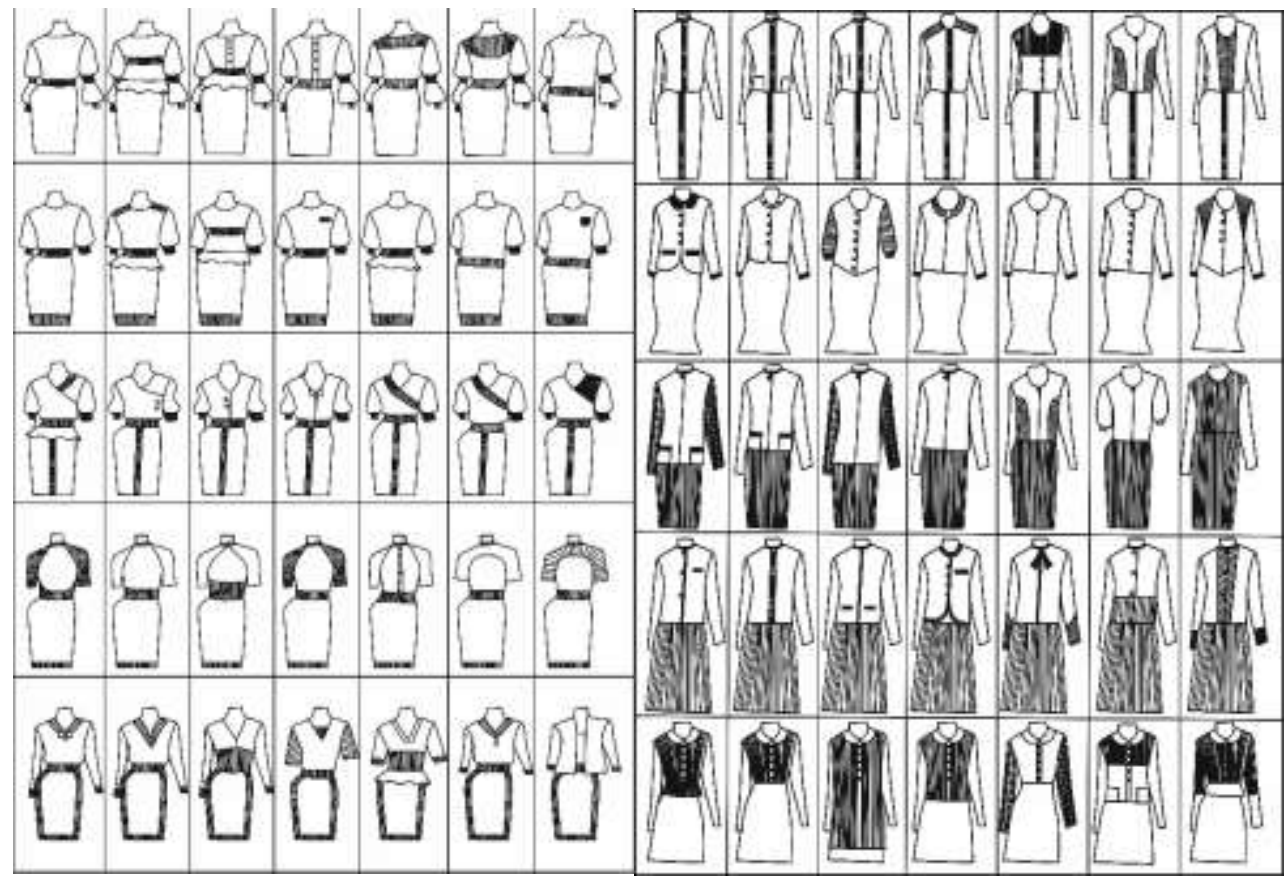

a

b

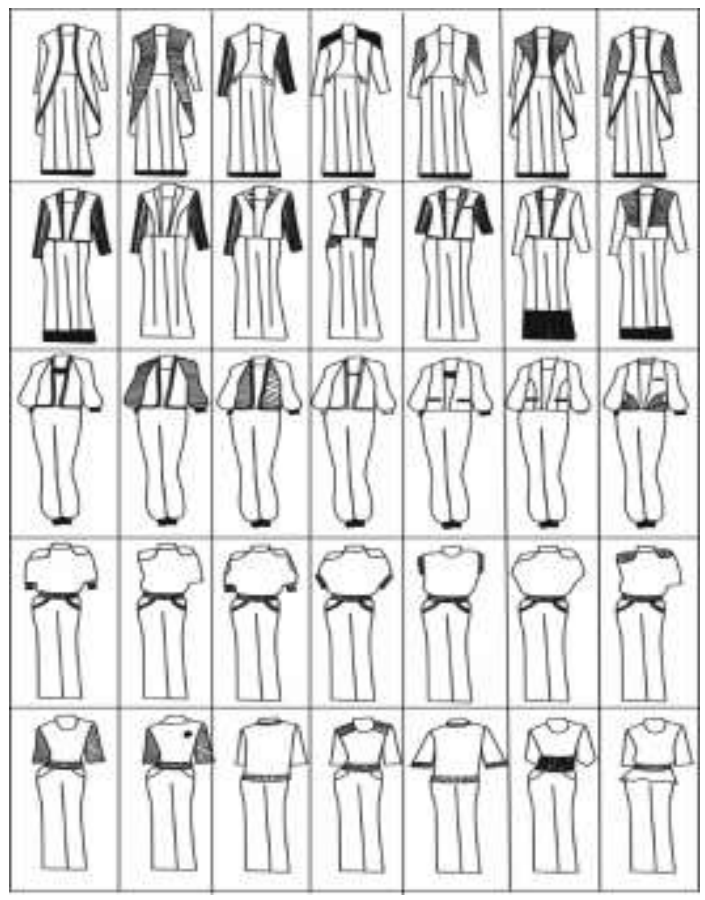

C

Fig. 1. Designing clothing models using the matrix method:

a. blouses and skirts; b. jackets and mini skirts; c. pants sets 
The OK leading silhouettes in the proposed collection are semi-adjacent knitted sets with different stretch zones (Fig. 1).

Using the matrix method, we have developed a number models of a female's blouse and a skirt of an adjacent and semi-adjacent silhouette made from semi-component outer knitwear (Fig.1, a).

These first row skirts horizontally in the same "mini" shape, adjacent silhouette. They can be developed froma low-stretch fabric mixture of $50 \times 4 / 1$ tex cotton yarn and 12,5 x 4/2 tex silk thread. Set-in sleeves view of a same cut blouse. On the blouse and sleeves to the elbow (1st model), chest (2nd model), waist (3rd model), on bottom the thighs (4th, 7th models), on the thighs and shoulder (5th, 6th

models) it is recommended to use new extensible knitted fabrics mixture of 50x4/1 tex cotton yarn, 12,5 $x 4 / 2$ tex silk thread and $4,44 \times 1$ tex elastomeric lycra thread.

The second row skirts horizontally are designed in the same silhouette, knee-length. It is recommended to use low stretch knitted fabrics on these skirts. The blouses sleeves cut does not differ from each other. On the waist, hip, chest, pockets, shoulder, the sleeve and skirt bottom, it is recommended to use new stretchable knitted fabrics mixture of $50 \times 4 / 1$ tex cotton yarn, 12,5 x 4/2 tex silk thread and 4,44 x 1 tex elastomeric lycra thread.

In the third row there are horizontally, single-breasted and double-breasted blouses, the shelves which are on the side fasteners. Collar armholes are designed with different geometric shapes. It is recommended to use new stretchable knitted fabrics mixture of $50 \mathrm{x}$ 4/1 tex cotton yarn and 12,5 $\times 4 / 2$ tex silk thread on the ledge collars armhole, jacket bottom, sleeves and on the front panel center of the skirt.
On the fourth row of this matrix are proposed blouses and skirts of an adjacent silhouette. The blouse front is designed in one-piece and single-breasted with raglan sleeves. On this row, low-stretch knitted fabrics from $50 \times 4 / 1$ tex cottonyarn mixture and $12,5 \times 4 / 2$ tex silk thread are recommended for the "stand-up" collar $(1,4,7$ models), the blouse and skirt bottom.

On the fifth row, the blouse collars are designed in a triangular shape. For the first, second and sixth models collars are recommended stretchable knitted fabrics. On the third and fourth models collars armholes is recommended a thin edging, and on the fifth model a strap. The sleeves, collars bottom, the waist area of the skirt, the skirt side bottom parts, from the chest area ( 3,5 models) to the blouse bottom are recommended low-stretch (cotton fabric +s) knitted fabrics.

Figure $1, \mathrm{~b}$ shows collections series of female's suits models of an adjacent and semi-adjacent silhouette developed by us. The first row jackets differ from each other by the ledge fasteners, collars, pockets, side parts, pagons and yokes. Low-stretch (cotton fabric+ s) knitted fabrics are recommended for sleeves, set-in pockets, jacket backs, main ledge details, the back and front panels side details of the skirt. Jacket collars (1st, 2nd, 3rd models), sides (1, 2, 3, 4, 7th models), on the shoulder pagon (4th model), on the ledge yoke (5th model), the jacket side (6th model) and on the skirt center can be used with stretchable (cotton fabric $+s+1)$ knitted fabrics.

The second row jackets of models differ in length, silhouette, bottom shape, ledge fasteners, collars and pockets. Low-stretch (cotton fabric $+s+l$ ) knitted fabrics are recommended for extensions on the semiadjacent skirt bottom. You can use stretchable (cotton fabric $+\mathrm{s}+\mathrm{l}$ ) knitted fabrics on collars (1st and 4th models), sleeves bottom (all models), on sleeves (3rd model) and on pocket flaps (1st model). 
The designed jackets on the third row differ from each other in thigh-length (1st, 3rd models), adjacent silhouettes (5th, 6th models) and sleeve length (6th model). To design jacket set-in pockets (1st, 2nd models) and sleeves (1st, 3rd models), ledge side details (5th model), the sleeve bottom (6th model), ledge (7th model), front and back skirts panels, it is proposed to use stretchable (cotton fabric $+s+l$ ) knitted fabrics.

The fourth row jackets differ in the ledge clasps (2nd, 6th, 7th models), the collar armhole (4th model), pocket flaps (1st, 4th models), the sleeve bottom (5th, 7th models) and the shelves (4th, 6th models). To the ledge center (2nd, 4th, 7th models), pocket flaps (1st, 3 rd models), the sleeves bottom (5th, 7th models), jacket below the waist (6th model), the front and back skirts panel can be developed from an expandable (cotton fabric $+\mathrm{s}+\mathrm{l})$ knitted fabric.

The 5-row collection model horizontally focuses on the fitted and semi-fitted silhouette of the female suit. Jacket lengths suggested to the hips and knees (1st, 2nd, 5th, 7th models) with fitted silhouettes. The fourth model is semi-adjacent, and the third is straight silhouette.

This series skirts models do not differ. The jacket ledge $(1,2,3,4,7$ th models), yoke (6th model), set-in sleeves (5th, 7th models) can be developed from stretchable (cotton fabric $+\mathrm{s}+\mathrm{l})$ knitted fabric.

The next row of the model's collection (Fig. 1, c) is aimed at female's pantsuits. On the first row, jackets have been designed without fasteners, with long setin sleeves and wide trousers. The jackets offered on the second row are designed with collars, without front fasteners, with long and short set-in sleeves, without sleeves and fitted trousers. On the third row, waist-length jackets with raglan sleeves, no fasteners and tight trousers are designed. The blouses offered on the fourth row are designed with one-piece short sleeves. Trousers are long, semi-adjacent silhouette. On the fifth row are proposed horizontally, blouses and skirts of an adjacent and semi-adjacent silhouette.

These pantsuits can also be designed from stretchable and low stretch knitted outerwear.

\section{CONCLUSIONS}

The scientific research results have shown that the new whole-cut multi-component outer knitted fabrics developed by us are comfortable, form-stable, hygroscopic, hygienic, and resistant to operational properties. From these knitted fabrics can be developed different models designs of female's outerwear.

The next direction of scientific research is the sketchy models development of female's knitwear.

\section{REFERENCES}

1. Koblyakova EB Basics of design of rational sizes and uniforms / E.B.Koblyakova. - M: Legkaya and pishchevaya prombshlennost, 1984.-280 p.

2. Nabidjanova NN Development of technologies and design of a new assortment of cotton-silk verxnix knitted products: author. dis... kand. techn. science / N.N.Nabidjanova.- Tashkent: TITLP, 2008.-19p.

3. Nigmatova FU, Alimova $X$ Development of methods of designing assortment of clothes from natural leather // Tashkent: "Science and Technology Center", 2013.-304 p.

4. Abdukarimova M.A. Development of technology of formation of rational assortment of women's clothing. dis... kand. techn. science / M.A. Abdukarimova-Tashkent: TITLP, 2003-138 p.

CSLKFI - Cotton, silk, lycra knitted fabric CDMDII - Clothing design, modeling and design 